\title{
ESTUDIO COMPARATIVO ENTRE LOS ORDENAMIENTOS JURÍDICOS ESPAÑOL Y JAPONÉS ACERCA DE LA RESPONSABILIDAD POR DAÑOS MORALES DERIVADOS DE LA INFIDELIDAD CONYUGAL
}

\author{
COMPARATIVE STUDY OF THE SPANISH AND THE JAPANESE \\ LEGAL SYSTEMS REGARDING LIABILITY DUE TO MORAL \\ DAMAGES CAUSED BY MARITAL INFIDELITY
}

\author{
MARÍA IsABel Domínguez YAMASAKI \\ Doctora en Derecho Privado \\ Abogada \\ Profesora-tutora UNED
}

Recibido: 15.12.2020 / Aceptado: 12.01.2021

DOI: https://doi.org/10.20318/cdt.2021.5958

\begin{abstract}
Resumen: La admisibilidad de la responsabilidad civil por daños morales en el Derecho de familia es una las cuestiones que en la actualidad es objeto de debate en la doctrina y que, como nuestro propio Tribunal Supremo reconoce, plantea los mismos interrogantes en el Derecho comparado. Así pues, el objeto de este trabajo consiste en una comparación entre los ordenamientos jurídicos español y japonés respecto de la responsabilidad civil por daños morales derivados de la infidelidad conyugal, dadas las similitudes que presentan los códigos civiles de ambos países en contraste con las soluciones opuestas adoptadas por los mismos. Las mencionadas similitudes ponen de manifiesto la importancia de las consideraciones éticas y morales a la hora de proporcionar una solución a los supuestos en los que se constata la producción de un daño moral con motivo del incumplimiento del deber de fidelidad que se deben los cónyuges.
\end{abstract}

Palabras clave: responsabilidad civil, daños morales, infidelidad conyugal.

Abstract: Nowadays, the possibility of determining a liability for moral damages in the field of Family Law is one of the issues which is subject of debate by the doctrine and, as our Supreme Court recognizes, raises the same questions in Comparative Law. Therefore, the subject matter of this paper is a comparison between both Spanish and Japanese legal systems in respect of liability due to moral damages caused by marital infidelity, considering the similarities between both countries' civil codes in contrast with the opposing solutions given by these countries. The aforementioned similarities bring into light the importance of ethical and moral considerations in order to provide a solution to those cases in which a moral damage is provoked on the occasion of the infringement of the fidelity duty between the spouses.

Keywords: liability, moral damages, marital infidelity.

Sumario: I. Punto de partida: El Código Civil Japonés (民法) y el Código Civil Español. 1. Acercamiento al Código Civil Japonés (民法). 2. Regulación de los deberes conyugales y de la responsabilidad civil. A) Los deberes conyugales. B) La responsabilidad civil. II. Rechazo de la responsabilidad civil por daños morales derivados de la infidelidad conyugal en España. 1. Introducción. La sentencia del Pleno de la Sala de lo Civil 629/2018, de 13 de noviembre, como referencia. 
2. Cautelas respecto de los juicios de moralidad. 3. El deber de fidelidad: entre deber moral y deber jurídico. 4. Ausencia de regulación de las consecuencias jurídicas derivadas del incumplimiento del deber de fidelidad. 5. Inidoneidad de la admisión de la responsabilidad civil en las relaciones matrimoniales. III. Admisión de la responsabilidad civil por daños morales derivados de la infidelidad conyugal en Japón 1. Introducción. A) Reforma del Código Civil Japonés tras la Constitución Japonesa de 1947. B) Modalidades de divorcio en Japón y su incidencia. C) Concepto de infidelidad en el ordenamiento jurídico japonés. 2. Fundamentos. 3. Tipos de responsabilidad. A) La responsabilidad civil del cónyuge infiel. Distinción entre la responsabilidad civil por divorcio y la responsabilidad civil por infidelidad. B) La responsabilidad civil del amante del cónyuge infiel. Referencia a la sentencia del Tribunal Supremo japonés de 19 de febrero de 2019. IV. Conclusiones.

\section{Punto de partida: El Código Civil Japonés (民法) y el Código Civil Español}

\section{Acercamiento al Código Civil Japonés (民法)}

1. A la hora de realizar una valoración del tratamiento jurídico que recibe la pretensión de indemnización por daños morales a raíz de la infidelidad conyugal por los ordenamientos jurídicos español y japonés, el punto de partida no puede ser otro que lo previsto en sus respectivos códigos civiles, puesto que son los textos legales donde se regulan tanto la institución del matrimonio como las normas básicas sobre la responsabilidad civil.

2. Merece ser destacado, en primer lugar, que en la elaboración del Código Civil japonés vigente que data del año 1898 - (民法, minpô) se prescindió de la influencia china pasando a inspirarse el legislador japonés en las escuelas anglosajona, francesa y, sobre todo, alemana. De este modo, a pesar de las profundas diferencias sociológicas y culturales que separan a ambos países, una vez que en Japón se optó por una regulación en materia de Derecho civil que responde primordialmente a nuestra tradición romana, se observa que las similitudes entre los códigos civiles español y japonés son mayores de lo que cabría suponer ${ }^{1}$.

3. Entre las vicisitudes que se produjeron en el proceso de elaboración del Código Civil japonés, nos encontramos con que el proyecto del texto normativo elaborado por el grupo de trabajo encabezado por BOISSONADE - concluido en 1889- fue rechazado, entre otros motivos, por considerarse que la influencia francesa era excesiva. De este modo, entre las razones por las que el referido proyecto fue objeto de crítica era que la tradición japonesa había de tener mayor reflejo en las normas referidas a las relaciones familiares ${ }^{2}$. De otra parte, en el caso del proceso codificador español, es cierto que sobre el Proyecto de Código Civil de 1851 el modelo francés también ejercía una importante influencia, aunque a diferencia del Código de BoISSONADE de 1889, el principal motivo por el que el Proyecto de 1851 fracasó fue la oposición ejercida por los partidarios de la conservación de los Derechos forales en nuestro ordenamiento jurídico ${ }^{3}$.

4. A modo de conclusión de esta breve introducción al Código Civil japonés debo señalar que éste fue objeto de profundas reformas en materia de Derecho de familia tras la Segunda Guerra Mundial, con la sustitución de la Constitución Meiji de 1889 (明治憲法, Meiji-kenpô), cuyos principios básicos eran la soberanía imperial, la reserva de ley y la constitucionalidad del Gobierno, por la Constitución

${ }^{1}$ F. Barberán / R. Domingo, Código Civil Japonés, Aranzadi, Cizur Menor, 2006, pp. 25 y ss. En particular, los autores señalan, asimismo, que en la redacción del Código Civil japonés se pudo tener en cuenta el Código Civil español, constando anotaciones originales en las que se hacía referencia a diversos artículos de nuestro Código Civil — pp. 41 a 44 .

${ }^{2}$ K. Steiner, "Postwar Changes in the Japanese Civil Code", Washington Law Review, Vol. 25, No. 3, 1950, p. 287; G. F. Margadant, Evolución del Derecho Japonés. Introducción histórico-sociológica al sistema jurídico del Japón actual, Miguel Ángel Porrúa, México, 1984, p. 152; N. Kano, "Reform of the Japanese Civil Code-The Interim Draft Proposal of 2013", Journal of Japanese Law, No. 36, 2013, pp. 250 a 252. Por su parte, sobre el proceso de elaboración del Código Civil japonés destacan especialmente F. BARBerÁn/R. Domingo, Op. Cit., pp. 25 a 54.

${ }^{3}$ F. De Castro, Derecho Civil de España, Vol. I, Civitas, Cizur Menor, 2008, pp. 29 a 213. 
elaborada a instancia del General MacArthur — que entró en vigor en $1947{ }^{4}$, cuyos principios básicos habían de ser —y efectivamente son — la soberanía popular, el pacifismo y la cooperación internacional ${ }^{5}$.

5. De esta forma, en lo que respecta a las normas reguladoras del matrimonio, las modificaciones que se llevaron a cabo fueron a consecuencia del reconocimiento constitucional de la igualdad entre sexos; de tal modo que la materialización de los cambios constitucionales a propósito de la igualdad entre hombre y mujer se produjo con la reforma de las normas dedicadas a la ordenación del matrimonio en el Código Civil por medio de la Ley 152/1947, de 6 de diciembre, de procedimiento sobre relaciones familiares (家事審判法, kajishinpanhô), la Ley 222/1947, de 22 de diciembre, de reforma parcial del Código Civil (民法の一部を改正する法律, minpôno ichibuwo kaiseisuru hôritsu) y la Ley 224/1947, de 22 de diciembre, de registro familiar (戸籍法, kosekihô).

\section{Regulación de los deberes conyugales y de la responsabilidad civil}

\section{A) Los deberes conyugales}

6. Entre los artículos del Código Civil japonés — «CCJap» en lo sucesivo- dedicados a la regulación del matrimonio se encuentra el art. 752 en el que se prevén los deberes de convivencia, colaboración y ayuda mutua entre los cónyuges (同居, 協力及び扶助義務, dôkyô, kyôryoku oyobi fujogimu). En este sentido, acerca del deber de colaboración mutua, en el Capítulo Tercero de la Constitución Japonesa, bajo la rúbrica «De los derechos y deberes de los ciudadanos», en el primer párrafo del art. 24 se consagra dicho deber de colaboración, al mismo tiempo que prevé la igualdad de derechos entre los cónyuges ${ }^{6}$ - en el caso de nuestra Constitución, en su art. 32 se dispone el reconocimiento de la igualdad jurídica de los cónyuges-.

7. Aunque el CCJap prevea estos tres deberes conyugales de manera bastante parecida a los deberes que se establecen en los arts. 67 y 68 del CC español, es sabido que el art. $68 \mathrm{CC}$ incluye el deber de los cónyuges de guardarse fidelidad. En consecuencia, la primera diferencia que se detecta en relación con los deberes conyugales previstos en los códigos civiles español y japonés es que el deber de fidelidad se encuentra recogido exclusivamente en nuestro Código Civil.

8. En cambio, la cuestión relativa al deber de fidelidad, o más bien su incumplimiento, es tenida en cuenta en el CCJap en lo que respecta al divorcio, puesto que en él se opta por un sistema causal para el divorcio contencioso, de manera que en el art. 770.1.1 CCJap la infidelidad conyugal constituye una de las causas justificativas de la estimación de la demanda de divorcio, disponiendo que «[u]n cónyuge sólo podrá formular demanda de divorcio por las siguientes razones: a. Cuando el otro cónyuge hubiere cometido un acto de infidelidad conyugal. (......» ${ }^{7}$. Por su parte, en España, tras la reforma operada por la Ley 15/2005, de 8 de julio, por la que se modifican el Código Civil y la Ley de Enjuiciamiento Civil en materia de separación y divorcio, en el Código Civil se suprimieron las causas de separación recogidas en su art. 82, entre las que se incluía el incumplimiento del deber de fidelidad.

\footnotetext{
${ }^{4}$ También conocida como la «Constitución de la paz» (平和憲法, heiwa-kenpô) o «Constitución de la posguerra» (戦後 憲法, sengo-kenpô)

${ }^{5}$ M. IKeda / S. Rodríguez Artacho, con la colaboración de K. Kuroda / F. Barberán, "Derecho constitucional”, en Introducción al Derecho Japonés Actual, F. BARBerán / K. Kuroda / F. OKabe (Coord.), Aranzadi, Cizur Menor, 2013, pp. 56 a 61.

${ }^{6}$ De acuerdo con la versión oficial en inglés de la Constitución Japonesa, dice así el art. 24: «Marriage shall be based only on the mutual consent of both sexes and it shall be maintained through mutual cooperation with the equal rights of husband and wife as a basis.

With regard to choice of spouse, property rights, inheritance, choice of domicile, divorce and other matters pertaining to marriage and the family, laws shall be enacted from the standpoint of individual dignity and the essential equality of sexes»». Enlace web: https://japan.kantei.go.jp/constitution_and_government_of_japan/constitution_e.html

${ }^{7}$ La transcripción de los artículos del CCJap a lo largo de todo el trabajo se realiza con base en la traducción de F. BARBERÁN /R. Domingo, Op. Cit.
} 
9. En la Exposición de Motivos de La Ley 15/2005, de 8 de julio, se indica que «[e]l divorcio se concebía como último recurso al que podrían acogerse los cónyuges y sólo cuando era evidente que, tras un dilatado periodo de separación, su reconciliación ya no era factible. Por ello, se exigía la demostración del cese efectivo de la convivencia conyugal, o de la violación grave o reiterada de los deberes conyugales, una suerte de pulso impropio tendido por la ley a los esposos, obligados bien a perseverar públicamente en su desunión, bien a renunciar a tal expresión reconciliándose. En ningún caso, el matrimonio podía disolverse como consecuencia de un acuerdo en tal sentido de los consortes». Así pues, más adelante según reza dicha exposición de motivos, con la eliminación del divorcio causal del CC español, se pretendía «que la libertad, como valor superior de nuestro ordenamiento jurídico, tenga su más adecuado reflejo en el matrimonio».

10. No obstante, el mantenimiento del sistema de causal de divorcio en Japón no supone, sensu contrario, que la libertad de los cónyuges esté limitada en los mismos términos en que así se preveía en nuestro CC anterior a la modificación operada por la Ley 15/2005, de 8 de julio. De hecho, como veremos más adelante, el divorcio consensuado o de mutuo acuerdo ya se encontraba previsto en el CCJap en su redacción original — con sus luces y sus sombras -8 y su inclusión en dicho texto respondía precisamente a la tradición japonesa en relación con la disolución del matrimonio.

\section{B) La responsabilidad civil ${ }^{9}$}

11. En lo atinente a la normas sobre responsabilidad civil, el art. 709 CCJap, que regula la «indemnización de daños y perjuicios por acto ilícito» (不法行為による損害賠償, fuhôkôiniyoru songaibais$h o ̂)$, prevé que «[e]l que dolosa o culposamente lesione derechos o bienes ajenos jurídicamente protegidos quedará obligado a la indemnización de los daños y perjuicios ocasionados». Se comprueba que el art. 709 CCJap y nuestro art. 1902 CC son bastante similares, si bien en dicho artículo del CCJap se hace referencia expresa a la antijuricidad del daño, en tanto que la lesión ha de recaer sobre derechos o bienes ajenos jurídicamente protegidos, mientras que el art. 1902 CC se limita a expresar que «[e]l que por acción u omisión causa daño a otro, interviniendo culpa o negligencia, está obligado a reparar el daño causado» entendiéndose que tal daño ha de ser, efectivamente, antijurídico - ${ }^{10}$. Sin embargo, por su parte, el CCJap prescinde de la mención al tipo de conducta, activa u omisiva, como sí hace, en cambio, el art. 1902 CC.

12. Ahora bien, respecto de la regulación de la responsabilidad civil en ambos países, si en nuestro caso la responsabilidad por daños morales es fruto de la interpretación jurisprudencial realizada del art. $1902 \mathrm{CC}^{11}$, es digno de mención que el art. 710 CCJap regula expresamente la indemnización

${ }^{8}$ De acuerdo con K. Steiner, Op. Cit., pp. 302 y 303, muchos divorcios que se producían de manera «consensuada», en realidad, encubrían la «expulsión» de la esposa por parte de la familia del marido. Aunque, según indican F. BARBERÁN /R. Domingo, Op. Cit., pp. 45 y 46, con el CCJap de 1898 se eliminó el «divorcio unilateral» o repudio, introduciéndose en el ordenamiento jurídico japonés el divorcio consensuado o de mutuo acuerdo y, de otra parte, el divorcio «con justa causa».

${ }^{9}$ En este trabajo se mantiene la postura según la cual los daños morales que pudiesen derivar del incumplimiento del deber de infidelidad habrían de indemnizarse, en su caso, por la vía de la responsabilidad civil ex art. 1902 CC, siguiendo la línea mantenida por autores tales como J. R. De Verda y Beamonte / P. Chaparro Matamoros, "La responsabilidad civil en el ámbito de las relaciones familiares en España”, Actualidad Jurídica Iberoamericana, núm. 4 ter, julio de 2016, que así lo manifiestas en las pp. 220 y 232; C. De AmunÁtegui Rodríguez, "El valor de los deberes personales entre los cónyuges: incumplimiento del deber de fidelidad", en La responsabilidad civil por daños en la relaciones familiares”, J. A. García Amado, (Dir.), P. Gutiérrez Santiago / M. Ordás Alonso (Coord.), Bosch, Barcelona, 2017, pp. 24 y 25.

${ }^{10}$ Según el art. 5191-3 de la Propuesta de Código Civil elaborado por la Asociación de Profesores de Derecho Civil, el daño se define como «cualquier lesión o menoscabo de un bien jurídico, ya se un derecho o ya sea un interés jurídicamente protegido». Asociación de Profesores de Derecho Civil, Propuesta de Código Civil, Tecnos, Madrid, 2018.

${ }^{11}$ J. Santos Briz, “Artículo 1.902”, en Comentarios al Código Civil y Compilaciones Forales, Tomo, XXIV, M. AlbaladeJo (Coord.), Edersa, Madrid, 1984, p. 167, señala, aparte de la STS de 6 de diciembre de 1912 por la que se cambió de criterio respecto de la posibilidad de indemnización por daños morales, las siguientes sentencias en este sentido con fecha de 14 de diciembre de 1917, de 7 de noviembre de 1919, de 11 de marzo de 1928, de 31 de marzo de 1930, de 19 de mayo de 1934, de 3 de junio de 1942, de 25 de junio de 1945, de 24 de mayo de 1947 y de 9 de diciembre de 1949. 
por daños no patrimoniales (財産以外の損害の賠償, zaisan-igaino songaino baishô). Así pues, según dispone el artículo citado: «[c]on independencia de que lo dañado haya sido la integridad física, la libertad o el honor de una persona, o sus derechos patrimoniales, la persona que, de conformidad con el lo dispuesto en el artículo anterior, esté obligada a indemnizar los daños y perjuicios causados, vendrá también obligada al pago de una compensación por los daños de naturaleza no patrimonial» ${ }^{12}$. Constatándose, en consecuencia, que las normas de ambos ordenamientos que regulan la responsabilidad civil guardan bastante relación.

13. A mi juicio, no obstante, la coincidencia más reseñable entre los sistemas de responsabilidad civil español y japonés es la que se refiere a que la función primordial en ambos supuestos es la de la reparación del daño basado en la culpa - aunque en ambos países se admite la responsabilidad objetiva en determinados supuestos-, incluyéndose en la regla contenida en los arts. 1902 CC y 709 CCJap un componente de índole moral según el cual solo responde de los daños quien haya llevado a cabo una conducta dolosa o negligente; lo que supone, asimismo, la consagración de la confianza y el deber de diligencia en el desarrollo de la vida en sociedad ${ }^{13}$. Aparte, si bien esta consideración no es del todo pacífica, un sector de la doctrina entiende que el elemento culposo de la acción provoca que la figura de la responsabilidad civil tenga asimismo un carácter preventivo ${ }^{14}$. Pero, dejando al margen la posible función preventiva de esta institución, la función eminentemente reparadora de la responsabilidad civil tanto en España como Japón es especialmente relevante a la hora de valorar las soluciones opuestas por las que han optado ambos ordenamientos en cuanto al reconocimiento o no de la responsabilidad civil por daños morales derivados de la infidelidad conyugal.

14. Como reconoce el Pleno de la Sala de lo Civil en su sentencia 629/2018, de 13 de noviembre, nos encontramos ante «una de las cuestiones, no solo de mayor complejidad, sino de mayor actualidad del derecho de familia, tanto en el ámbito de la doctrina científica, como en el de las Audiencias Provinciales y en el derecho comparado, con posiciones contrarias sobre la aplicación de la normativa propia de la responsabilidad civil extracontractual en las relaciones de familia, (...)».

\section{Rechazo de la responsabilidad civil por daños morales derivados de la infidelidad conyugal en España}

\section{Introducción. La sentencia del Pleno de la Sala de lo Civil 629/2018, de 13 de noviembre, como referencia}

15. Cuando en nuestro país se ha planteado la admisibilidad o no de resarcir los daños morales sufridos con motivo de una infidelidad conyugal, el primer interrogante que ha surgido ha sido el de la determinación de la naturaleza jurídica del deber de fidelidad. De esta forma, la decisión sobre la referida pretensión de indemnización se sustenta en la postura por la que se opte acerca de si dicho deber tiene la consideración de auténtico deber jurídico o si, por el contrario, consiste en un deber de carácter meramente ético o moral y que, además, su incumplimiento no genera otra consecuencia jurídica que las previstas en el art. 152.4 sobre el cese de la obligación de dar alimentos, el art. 855.1 $1^{\circ}$ como causa de desheredación del cónyuge y el art. $1343.3^{\circ} \mathrm{CC}$ en relación con la revocación de las donaciones realizadas por los contrayentes entre sí.

\footnotetext{
${ }^{12}$ Asociación de Profesores de Derecho Civil, Op. Cit., en el art. 5192-1 de dicha propuesta se prevé que los daños resarcibles son «tanto los daños patrimoniales como los extrapatrimoniales».

${ }^{13}$ R. De Ángel Yágüez, "Fundamento de la responsabilidad civil", en Tratado de Responsabilidad Civil, Tomo I, I. SIERRA Gil de la Cuesta (Coord.), Bosch, Barcelona, 2008, pp. 126 y 127; L. Dízz-Picazo y Ponce de León, Fundamentos del Derecho Civil Patrimonial, Tomo V, Civitas, Cizur Menor, 2011, p. 20.

${ }^{14}$ F. Peña López, “Art. 1902”, en Comentarios al Código Civil, Tomo IX, R. Bercovitz Rodríguez-Cano (Dir.), Tirant Lo Blanch, Valencia, 2013, p. 12961.
} 
16. De hecho, respecto de la naturaleza jurídica del deber de fidelidad, con la supresión del divorcio causal parece haberse desnaturalizado dicho deber, dada la limitación de las consecuencias jurídicas que generan su incumplimiento ${ }^{15}$. En este sentido, en el razonamiento seguido por la STS 701/1999, de 30 de julio de 1999, a la vez que se reconoce el reproche ético que puede merecer el incumplimiento de los deberes conyugales, y más aún cuando se trata del deber de infidelidad, se sostiene que «(...), es indudable que la única consecuencia jurídica que contempla nuestra legislación substantiva es la de estimar su ruptura como una de las causas de separación matrimonial en su artículo 82 pero sin asignarle, en contra del infractor, efectos económicos, (...), pues lo contrario llevará a estimar que cualquier causa de alteración de la convivencia matrimonial, obligaría a indemnizan». De lo transcrito se pueden desprender dos ideas. La primera, según la cual podría interpretarse que la postura mantenida por el Alto Tribunal parece apoyarse en el hecho de que la previsión del sistema de separación causal del anterior art. $82 \mathrm{CC}$ suponía una reacción suficiente del ordenamiento jurídico frente al incumplimiento del deber de fidelidad. Y la segunda, la consideración de que la posibilidad de admitir una indemnización por daños morales en estos supuestos implicaría tener que indemnizar por cualquier incumplimiento de un deber conyugal.

17. En nuestro país, los pronunciamientos judiciales sobre el deber de fidelidad se han producido, principalmente, a propósito de los supuestos relativos a la ocultación de la paternidad del marido respecto de los hijos nacidos de una relación extraconyugal de la esposa. La última sentencia del Pleno de la Sala de lo Civil relacionado con el deber de fidelidad es la de 629/2018, de 13 de noviembre; sin embargo, los daños morales se alegaron en relación con una pretensión de indemnización cuya causa no era la infidelidad conyugal en sí, sino la ocultación de la paternidad del demandante sobre uno de los hijos habidos constante el matrimonio. Es decir, dicha pretensión de indemnización por daños morales se refería a las consecuencias derivadas de una conducta negligente a propósito de una infidelidad conyugal.

18. El propio tribunal manifiesta en dicha sentencia que «[e]s cierto que la sentencia ha relacionado el daño no con la infidelidad matrimonial (normalmente oculta), sino con la ocultación de los efectos de la infidelidad, en este caso de un hijo que se ha tenido como tal sin serlo (los efectos pueden ser otros). Al margen de que lo que lleva a la ocultación es el incumplimiento del deber de fidelidad, razones análogas a las expuestas en relación con este incumplimiento, resultan de aplicación cuando la conducta generada causante del daño es la ocultación de la filiación». Por tanto, para la exposición de los aspectos que entiendo más relevantes acerca de la responsabilidad civil por daños morales derivados de la infidelidad conyugal — y no de la ocultación de la oportunidad—, sirven de referencia las razones proporcionadas en la sentencia que nos ocupa.

19. Así pues, el fallo de la STS 629/2018, de 13 de noviembre, por la que se rechaza se la indemnizabilidad de esta modalidad de daño se fundamenta en lo siguiente: a) en primer lugar, porque supondría la realización de «un juicio de moralidad indudablemente complejo y de consecuencias indudablemente negativas para el grupo familiar»; b) en segundo término, se entiende que el daño indemnizable no tiene su origen en el incumplimiento del deber de fidelidad, sino "en la condición de persona afectada por la acción culposa o negligente de quien lo causa»; c) y, en último lugar, partiendo de que el Derecho de familia se caracteriza por ser una regulación específica y realizada de manera detallada, no es posible admitir la indemnización en este contexto cuando nada se ha previsto sobre la responsabilidad civil por daños morales como consecuencia jurídica derivada del incumplimiento de los deberes conyugales. No obstante, a continuación me centraré en exclusiva en los aspectos más relevantes relacionados con los motivos primero - a) - y tercero - c) - al considerar que el segundo de los motivos, haciendo referencia a la condición del afectado y de quien causa el daño, está fuera de lugar cuando tales condiciones subjetivas son inherentes a las vicisitudes que puedan darse en el seno de un matrimonio, ya que son los cónyuges quienes asumen los deberes conyugales el uno respecto del otro.

\footnotetext{
${ }^{15}$ Vid. L. LÓPEZ DE LA CRUZ, "La responsabilidad civil por los daños morales ocasionados en el ámbito familiar a causa de la ocultación de la paternidad. Comentarios a la STS de 13 de noviembre de 2018 (RJ 2018, 5158)", Revista de Derecho Patrimonial, núm. 48/2019, p. 10 —versión digital—.
} 


\section{Cautelas respecto de los juicios de moralidad}

20. En su sentencia 629/2018, de 13 de noviembre, el Pleno de la Sala de lo Civil del Tribunal Supremo sostiene, sobre la pretensión de indemnización en el supuesto de autos, que: «[n]o se niega que conductas como esta sean susceptibles de causar un daño. Lo que se niega es que este daño sea indemnizable mediante el ejercicio de las acciones propias de la responsabilidad civil, contractual o extracontractual, a partir de un juicio de moralidad indudablemente complejo y de consecuencias indudablemente negativas para el grupo familiar».

21. En primer lugar, sobre dicha afirmación, obviando la referencia a la complejidad en las valoraciones - lo cual forma parte de la propia aplicación del Derecho-, cabría objetar que el perjuicio a la familia se produzca por la determinación de una indemnización por daños morales, dado el daño que provoca o puede provocar a una familia la crisis matrimonial causada por la infidelidad conyugal. Esto es, lo que esencialmente puede dañar a una familia es la propia infidelidad, no el resarcimiento de los daños morales que ocasione.

22. Pero, yendo a la idea principal contenida en lo transcrito, en lo concerniente el denominado juicio de moralidad, entiendo que, en realidad, dicho juicio ha sido realizado por el legislador al incluir el deber de fidelidad entre los deberes conyugales y al haberlo mantenido hasta la actualidad, a pesar de haber tenido la oportunidad de eliminarlo, por ejemplo, con la reforma operada por la Ley 15/2005, de 8 de julio. Es decir, en el momento en que esta cuestión ha de tratarse en un procedimiento civil al servir de base para la pretensión de indemnización por daños morales derivados del incumplimiento del deber de fidelidad, no se entra a valorar la moralidad o no de la conducta, sino si dicha conducta se ha producido o no.

23. Sin embargo, ha sido constante en nuestra doctrina la referencia a la relación entre el resarcimiento por daños morales provocados en el seno de una relación matrimonial y los juicios de moralidad. Así, por ejemplo, MARTíN CASALS y RIBOT IGUALADA sostienen que la tendencia actual en el ámbito del Derecho de familia es la contención del Estado acerca de la elevación de los deberes morales a la categoría de deber jurídico, puesto que al entrar en el terreno de la sexualidad se habría de llevar cabo un juicio de moralidad $^{16}$, lo que, a su vez, provocaría un aumento de la conflictividad ${ }^{17}$.

\section{El deber de fidelidad: entre deber moral y deber jurídico}

24. Tal como se ha puesto de manifiesto, sobre la idoneidad o no de la postura mantenida por el Tribunal Supremo acerca de la responsabilidad civil por daños morales provocado por la infidelidad conyugal la doctrina se encuentra divida, encontrando argumentos tanto a favor como en contra de dicha línea jurisprudencial. A mi juicio, lo fundamental en este debate es comenzar dilucidando si los deberes conyugales tienen la consideración de simples deberes morales o si, por el contrario, son deberes de naturaleza jurídica. En este sentido, tal vez, el problema principal que se da a la hora de aportar una respuesta a esta pregunta, que en principio puede parecer sencilla, es que hay un amplio margen para las consideraciones de tipo ético o moral — si bien esta afirmación no pretende dar a entender que el Derecho sea ajeno a lo ético o la moral— ${ }^{18}$.

\footnotetext{
${ }^{16}$ M. Martín Casals / J. Ribot Igualada, "Exclusión de responsabilidad civil en la ocultación por la madre de las dudas sobre la paternidad biológica de un hijo. Comentario a la STS de 13 de noviembre de 2018 (RJ 2018, 5158)", Revista Cuadernos Civitas de Jurisprudencia Civil, núm. 110/2019, p. 23 —versión digital—.

${ }^{17}$ J. Ferrer Riba, "Relaciones familiares y límites del derecho de daños", InDret, 04/2001, p. 15; M. Martín CASALS / J. Ribot Igualada, Op. Cit., p. 24.

${ }^{18}$ Como puso de manifiesto el Prf. D. Luis Díez-Picazo y Ponce de León, Fundamentos del Derecho Civil Patrimonial, Vol. I, Civitas, Cizur Menor, 2011, p. 59, acerca del principio general de buena fe recogido en el art. 7 CC, en virtud de la formulación de este principio, en dicha norma se produce el encuentro entre lo ético y lo jurídico.
} 
25. De hecho, la SAP de Cádiz, sección $2^{\text {a }}$, 125/2008, de 3 de abril, advierte de que, al final, en el centro del debate lo que se encuentra es la determinación de la propia naturaleza de la institución matrimonial. De tal manera que, según se explica en dicha sentencia, «[l] a garantía institucional del matrimonio insita a la consideración como derecho fundamental en la Constitución Española el de contraer matrimonio (art. 32) impone al legislador la necesidad de dotarla de contenido frente a otras instituciones de convivencia y fruto de ella es el establecimiento por el legislador de ese elenco de deberes, cuya garantía pasa necesariamente por su caracterización como auténticos deberes jurídicos. (...). Creemos que no se trata de deberes naturales relacionados con la ética personal de cada uno de los contrayentes, sino de deberes jurídicos por muy peculiares que puedan ser».

26. Por otro lado, a favor de la consideración de los deberes conyugales como auténticos deberes jurídicos, DE VERDA Y BEAMONTE y CHAPARRO MATAMOROS, defienden esta postura basándose en que si fuesen meras obligaciones de conciencia, no se encontrarían recogidas entre los efectos del matrimonio. $\mathrm{Y}$, además, de acuerdo con el tenor literal de los arts. 67 y $68 \mathrm{CC}$, los cónyuges deben o están obligados a cumplirlos; es decir, no son meras recomendaciones. Asimismo, no debe olvidarse que en el momento de la celebración del matrimonio, los contrayentes han de asumir tales deberes, de manera que su exclusión afectaría a la causa del negocio, lo cual se relaciona con la simulación y la reserva mental originadoras de la invalidez matrimonial ${ }^{19}$.

\section{Ausencia de regulación de las consecuencias jurídicas derivadas del incumplimiento del deber de fidelidad}

27. Entre las razones expresadas tanto por nuestra jurisprudencia como por nuestra doctrina, entiendo que el verdadero argumento por el que se rechaza la responsabilidad civil por el incumplimiento de los deberes conyugales es que dicha posibilidad no se encuentra prevista de modo expreso en nuestro ordenamiento jurídico, circunstancia que se pone en relación con la exclusión de la responsabilidad civil los daños morales provocados en el seno de las relaciones familiares.

28. Pues bien, distintas razones pueden servir de apoyo para la defensa de susodicho argumento, al no encontrarse esta modalidad de responsabilidad civil expresamente establecida en la norma. Así, parte de la doctrina sostiene, al igual que se hizo en la STS 629/2019, de 13 de noviembre, que la institución del matrimonio se encuentra regulada detalladamente, de manera que las consecuencias jurídicas que derivan de la infracción de los deberes conyugales son las que así se encuentran expresamente reguladas por la norma. Aparte de los ya citados anteriormente sobre el incumplimiento del deber de fidelidad - el cese de la obligación de dar alimentos, la desheredación del cónyuge y la revocación de las donaciones realizadas por los contrayentes entre sí-, sirva de ejemplo, en relación con el deber de respeto que se deben los cónyuges, que tanto la legislación civil como la penal se ocupan de los atentados más graves contra derechos tales como la libertad o la integridad ${ }^{20}$.

29. Contra esta idea según la cual el Derecho de familia es un sistema cerrado y completo, de manera que las consecuencias que deriven del incumplimiento de un deber conyugal serán aquellas que expresamente se prevean en las normas que regulan el matrimonio, la antes citada SAP de Cádiz, sección $2^{\text {a }}, 125 / 2008$, de 3 de abril, señala que el art. $1902 \mathrm{CC}$ y el antiguo art. $82 \mathrm{CC}$ «tienen un fundamento y una finalidad diversa. En un caso se trata de resolver la crisis matrimonial mediante la suspensión o extinción del vínculo matrimonial y en el otro de reparar el daño causado a uno de los cónyuges».

19 J. R. De Verda y Beamonte / P. Chaparro Matamoros, Op. Cit., p. 247. Y, en páginas anteriores, en las pp. 230 y 231, los autores realizan una recopilación de los autores a favor y en contra de la responsabilidad civil en relación con los deberes conyugales.

${ }^{20}$ J. Ferrer Riba, Op. Cit., pp. 14 a 16; C. De Amunátegui Rodríguez, Op. Cit., 2017, pp. 33 a 35. 


\section{Inidoneidad de la admisión de la responsabilidad civil en las relaciones matrimoniales}

30. Al argumento acerca de la no previsión de la responsabilidad civil derivada del incumplimiento de los deberes conyugales y, por tanto, su inadmisibilidad, cabe plantearse si la aplicación del art. 1902 CC requiere la existencia de una norma en la que se disponga expresamente la indemnizabilidad de una determinada conducta provocadora de un determinado daño ${ }^{21}$. Es decir, en la averiguación de la voluntad del legislador acerca de esta cuestión, cabría entender que, precisamente, habida cuenta de que la responsabilidad civil se encuentra prevista en el art. 1902 CC con carácter general, no es necesaria la concurrencia de una norma que expresamente prevea la responsabilidad civil en el marco de las relaciones matrimoniales.

31. Una vez planteada esta cuestión, siempre y cuando se admitiese que los deberes conyugales son deberes jurídicos, saldríamos del ámbito propio del Derecho de familia, desplazándonos al terreno de la responsabilidad civil. Así pues, lo siguiente que se debería aclarar es si los daños nacidos por el incumplimiento de estos deberes merecen ser resarcidos o no.

32. Recurriendo de nuevo a la SAP de Cádiz, sección $2^{\mathrm{a}}, 125 / 2008$, de 3 de abril, en ella se indica que el resarcimiento por daños morales con motivo de una infidelidad conyugal solo será posible si se cumplen las normas que rigen la responsabilidad civil, de tal forma que es necesaria «la prueba cumplida de un ilícito civil de cierta trascendencia, de la imprescindible constatación de la presencia de un daño económico y/o moral que deba ser resarcido, del nexo de causalidad adecuado entre el ilícito y el daño y de la culpa o dolo del cónyuge infractor»». En sentido parecido, dentro de nuestra doctrina se ha defendido esta posibilidad con base en el necesario cumplimiento de los requisitos antes mencionados. Así, por ejemplo, DE VERDA Y BEAMONTE y CHAPARRO MATAMOROS, señalan que la culpa en supuestos semejantes se produciría con el incumplimiento grave o reiterado de dicho deber, en los mismos términos en que se expresaba el art. $82 \mathrm{CC}$ antes de su modificación en el año $2005^{22}$. Con esta breve referencia, lo que pretendo dejar en evidencia es que el resarcimiento no se produciría por la mera existencia de una infidelidad conyugal, sino que deberían darse todos y cada uno de los requisitos que se prevén en el art. 1902 CC.

33. Son razonables las reticencias en cuanto a la posibilidad de resarcimiento de los daños morales causados por una infidelidad conyugal; ahora bien, también parece razonable admitir la responsabilidad en esta sede, ya que no sería una sanción a dicho incumplimiento, sino que la indemnización por tales daños solo se determinaría en el caso de que concurriesen todos los requisitos antes citados con la pretensión de resarcir unos daños morales previamente demostrados.

\section{Admisión de la responsabilidad civil por daños morales derivados de la infidelidad conyugal en Japón}

\section{Introducción}

\section{A) Reforma del Código Civil Japonés tras la Constitución Japonesa de 1947}

34. Antes de la importante reforma del CCJap que se llevó cabo tras la promulgación de la Constitución Japonesa de 1947, la legislación relativa a la institución del matrimonio se encontraba marcada por la desigualdad entre el hombre y la mujer. Así, el Código Penal japonés (刑法, keihô) preveía en su art. 183 el delito de adulterio cometido por la esposa (姦通罪, kantsûzai) —en cambio, la infidelidad

\footnotetext{
${ }^{21}$ P. Salvador Coderch / S. Ramos González / C. Gómez Ligüerre / A. Rubí Puig / Á. Luna Yerga / R. Milà Rafel, Derecho de Daños. Análisis, aplicación e instrumentos comparados, Universidad Pompeu Fabra, Barcelona, 2020, p. 24.

${ }^{22}$ Acerca del cumplimiento de los requisitos de la responsabilidad civil, J. R. De Verda y Beamonte / P. Chaparro MataMOROs, Op. Cit., pp. 232 y ss.
} 
del marido no tenía la consideración de delito-. En lo que respecta al CCJap, por un lado, de acuerdo con su art. 768 se prohibía la celebración de matrimonio por parte de la mujer divorciada a causa de su infidelidad con el que había sido su amante durante la relación matrimonial (相姦婚, sôkankon); y, de otra parte, la desigualdad entre los cónyuges en perjuicio de la mujer tenía su reflejo asimismo en lo concerniente a las causas del divorcio contencioso (裁判上の離婚, saibannjôno rikon), debido a que el divorcio se concedía únicamente en el supuesto de que la infidelidad la hubiese cometido la esposa a tenor de lo dispuesto por el antiguo art. 813 CCJap.

35. Sin embargo, una vez se produjo la equiparación entre los derechos de hombres y mujeres gracias a lo establecido por el art. 24 de la Constitución Japonesa de 1947, este principio de igualdad provocó la consiguiente modificación del CCJap afectando, por tanto, a las normas reguladoras del matrimonio. Así pues, se eliminó la prohibición de que la mujer divorciada contrajese nuevas nupcias con su amante una vez producido el divorcio a causa de su infidelidad y, a su vez, la infidelidad conyugal como causa de divorcio contencioso se previó cuando la relación extraconyugal la hubiese mantenido tanto el hombre como la mujer. De hecho, una vez producida la referida reforma, las referencias al «adulterio» (姦通罪, kantsûzai) son sustituidas por el concepto de «infidelidad»o «conducta infiel» (不 貞行為, futeikôi), ya que el término «adulterio» empleado aludía en exclusiva a los actos de infidelidad cometidos por la mujer ${ }^{23}$.

36. Hay que reconocer, no obstante, que la igualdad de derechos entre los cónyuges se fue gestando con anterioridad a la referida Constitución de 1947 materializándose en el reconocimiento de la grave ofensa que puede suponer para la esposa la infidelidad del marido. De esta forma, en la sentencia del Tribunal Supremo japonés (大審院, daishin'in) ${ }^{24}$ de 19 de diciembre de 1918 (大審院判決大正 7.12.19民禄24輯2364頁), a pesar de que la norma no reconocía la infidelidad del marido como causa del divorcio contencioso, en este supuesto se consideró que constituía una ofensa tal merecedora de la concesión del divorcio solicitado por la mujer ${ }^{25}$.

\section{B) Modalidades de divorcio en Japón y su incidencia}

37. En el ordenamiento jurídico japonés existen cuatro modos distintos por los que proceder al divorcio. En la redacción original del CCJap se preveían dos modalidades de divorcio, en primer lugar, el de mutuo acuerdo o consensuado (協議上の離婚, kyôgijôno rikon) y, en segundo lugar el divorcio contencioso o judicial (裁判上の離婚, saibanjôno rikon). Pero, a raíz de la entrada en vigor de la Ley 152/1947, de 6 de diciembre, se incorporan otras dos formas de divorcio al ordenamiento jurídico japonés, que son: el divorcio llevado a cabo por acto de conciliación ante el Juez de Familia y un mediador entre los cónyuges (調停離婚, chôteirikon) y, de otra parte, el divorcio que se produce por la resolución del Juzgado de Familia (審判離婚, shinpanrikon).

38. De esta forma, en primer lugar, los cónyuges pueden divorciarse de forma consensuada ( 協議上の離婚, kyôgijôno rikon), haciéndolo efectivo por medio de la correspondiente inscripción en el Registro de Familia. En segundo lugar, si los cónyuges no alcanzan un acuerdo, podrán proceder al divorcio a través de la solicitud de un acto de conciliación ante el Juzgado de Familia (調停離婚, chôtei-

\footnotetext{
${ }^{23}$ Autor desconocido, “Japanese Family Law”, Stanford Law Review, Vol. 9, No. 1, 1956, p. 152, en nota a pie de página se

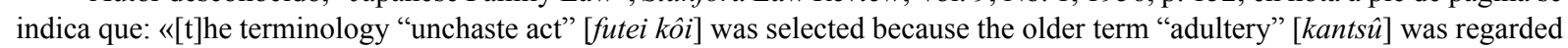
only as applying to a woman's extramarital activities. Minutes pf the Hearings Before the Judicial Committee, House of Councilors, $1^{\text {st }}$ National Diet, No. 27, at 4 (June 2, 1947) (explanation by government representative Okuno). Sobre esta cuestión, asimismo, K. SteIner, Op. Cit., pp. 292 y 293.

${ }^{24}$ Hasta 1947, el Tribunal Supremo japonés se denominaba «大審院》 (daishin'in) pero, después de la Segunda Guerra Mundial, con la Constitución de 1947, se creó un nuevo órgano jurisdiccional superior que se denominó «最高裁判所》 (saikôsaibansho).

${ }^{25}$ S. Minamikata, Family and Succession Law in Japan, Wolters Kluwer, The Netherlands, 2020, p. 85.
} 
rikon). Si el acto de conciliación fracasa, en tercer lugar, podrán los cónyuges solicitar la resolución del Juzgado de Familia por la que se les conceda el divorcio al haberse constatado que el matrimonio está efectivamente roto y que no hay posibilidad de que las partes lleguen a un acuerdo (審判離婚, shinpanrikon). Por último, cuando los intentos de conciliación anteriores han fallado, los cónyuges podrán solicitar el divorcio a través de demanda fundamentada en las causas de divorcio del art. 770 CCJap (裁 判上の離婚, saibanjôno rikon) ${ }^{26}$.

39. A diferencia de países de tradición católica como el nuestro, en Japón el divorcio consensuado ya era admitido alrededor del s. VIII. En este sentido, precisamente la previsión del divorcio consensuado en el CCJap — de influencia anglosajona, francesa y, sobre todo, alemana — respondía a la voluntad de que en él se reflejase la tradición japonesa en materia de Derecho de Familia. En cambio, la figura del divorcio contencioso sí que tenía menos aceptación por parte de la sociedad japonesa. Esta circunstancia se explica debido a que el divorcio era considerado una cuestión que debía quedar en la intimidad de las familias, de tal manera que el procedimiento de divorcio ante jueces y tribunales se consideraba en cierto modo deshonroso ${ }^{27}$. De hecho, el divorcio contencioso o judicial no tuvo apenas repercusión, en las dos primeras décadas del s. XX no llegó siquiera al 1\% de los divorcios que tuvieron lugar en Japón ${ }^{28}$.

40. Pues bien, en la actualidad, las tasas de divorcio contencioso siguen siendo bastante bajas en Japón, estimándose que en 2019 los divorcios por mutuo acuerdo aproximadamente supusieron el $88,1 \%$, el $8,8 \%$ tuvieron lugar a través de la mediación de los juzgados de familias y, por último, el divorcio contencioso tan solo alcanzó el $1 \%$ del total ${ }^{29}$, lo que representa el mantenimiento de la costumbre japonesa de evitar esta modalidad de divorcio.

\section{C) Concepto de infidelidad en el ordenamiento jurídico japonés}

41. Cabe señalar que la conducta infiel (不貞行為, futeikôi) en Japón es un concepto amplio que va más allá del tenor literal de la expresión y de significado muy distinto a lo que se considera infidelidad en nuestro ordenamiento jurídico. En el caso de España, el deber de fidelidad se entiende que va más allá de lo sexual, alcanzando el plano espiritual; consecuentemente, el deber de fidelidad se compone, asimismo, de la confianza y la lealtad entre los cónyuges ${ }^{30}$.

42. Así pues, en cuanto a la noción de conducta infiel a la que se refiere el art. 770.1.1 CCJap como causa de divorcio contencioso, la amplitud de dicho concepto no se refiere a lo espiritual sino a que llega a abarcar situaciones tales como la violación cometida por el cónyuge o la inseminación de la esposa con esperma de donante sin el consentimiento del marido. En cambio, si la infidelidad la hubiese cometido el cónyuge con una persona de su mismo sexo, dicha relación extramatrimonial no tendría la consideración de infidelidad en los términos previstos por el art. 770.1.1 CCJap, de tal manera que en estos supuestos, en un divorcio contencioso, habría de alegarse la cláusula general del art. 770.1.5 CCJap por el que esta forma de divorcio podrá producirse cuando «concurran otras causas que hagan difícil la continuación del matrimonio» ${ }^{31}$.

\footnotetext{
${ }^{26}$ F. Barberán / R. Domingo, Op. Cit., p. 384; S. Minamikata, Op. Cit., pp. 86 a 94; C. Danwerth, "Basic Principles of Japanese Family Law", Journal of Japanese Law, No. 31, 2011, p. 243.

${ }^{27}$ S. Minamikata, Op. Cit., pp. 84 y 85.

${ }^{28}$ F. Barberán / R. Domingo, Op. Cit., p. 46.

${ }^{29}$ Datos obtenidos del Portal de Estadísticas del Gobierno de Japón (政府統計の統合空口, seifutôkeino tôgômadoguchi). Enlace web: https://www.e-stat.go.jp/en/stat-search/files?page=1\&query=types\%20divorce\%20\&layout=dataset\&toukei=004 $50011 \&$ tstat $=000001028897 \&$ stat $\_$infid $=000031981603 \&$ metadata $=1 \&$ data $=1$

${ }^{30}$ R. Pérez Gallego, Op. Cit., p. 144.

${ }^{31}$ S. MinamiKata, Op. Cit., p. 94.
} 


\section{Fundamentos}

43. Aunque la doctrina jurisprudencial en Japón admite la indemnizabilidad de los daños morales (慰謝料, isharyô) ocasionados por la infidelidad conyugal, no solo considerando responsable al cónyuge infiel sino también a su amante bajo determinadas circunstancias, es preciso señalar que esta cuestión no es del todo pacífica en la doctrina japonesa. En consecuencia, debido a que el deber de fidelidad conyugal no constituye uno de los deberes conyugales establecidos por el CCJap y que tampoco se reconoce de modo expreso la responsabilidad civil derivada de la infidelidad conyugal, un sector doctrinal defiende que, si bien el deber de fidelidad ocupa un lugar de relevancia en la vida en común de todo matrimonio, esta es un cuestión que debería circunscribirse al ámbito de la moralidad en la vida privada $^{32}$.

44. No obstante, a pesar de que el deber de fidelidad no se encuentra expresamente previsto en el CCJap, la jurisprudencia y una parte importante de la doctrina entienden que su infracción se considera una conducta ilícita (不法行為, fuhôkôi), de tal manera que la indemnización por daños morales derivados de la infidelidad conyugal es admitida en aplicación de lo estipulado por los arts. 709 y 710 CCJap.

45. Desde esta posición mayoritaria, se entiende que tras las reformas operadas en la legislación japonesa adecuándola al principio constitucional de igualdad entre sexos, habían de preverse las medidas oportunas con el fin de proteger la institución del matrimonio. Es más, acerca de la ilicitud de la conducta, antes de la referida reforma, ya se puso de manifiesto dicha cuestión, de tal manera que en la sentencia del Tribunal Supremo japonés (大審院, daishin'in) de 20 de julio de1936 (大決大正 15.7.20刑集 5 券318頁) al entrar a examinar un supuesto sobre el tema que nos ocupa, se concluye que la infidelidad conyugal consiste en un ilícito civil, en tanto que afecta a la paz, la seguridad y la felicidad de la vida en común de los cónyuges. Una vez reformada la legislación relativa al matrimonio, en igual sentido se pronuncia la sentencia del Tribunal Supremo japonés (最高裁判所, saikô-saibanshô) de 1979 (裁判昭和54.3.30刑集33 券2号303頁), enfatizando la importancia de la protección de la paz y felicidad de la vida en familia ante conductas que pueden ser calificadas como incitación a la infidelidad y provocadoras de la ruptura del orden de una vida familiar saludable ${ }^{33}$.

46. Por otro lado, a pesar de que el deber de fidelidad entre los cónyuges no esté expresamente recogido en la norma japonesa salvo en cuanto a que constituye una de las causas de divorcio contencioso conforme al art. 770.1.1 CCJap, el hecho de que su incumplimiento sea generador de responsabilidad se ha sustentado, asimismo, en que el art. 732 CCJap prohíbe la bigamia al disponer que «[1]a persona que tenga cónyuge no podrá contraer simultáneamente otro matrimonio», de manera que el matrimonio japonés, al igual que el español, es una institución monógama y, consecuentemente, se considera que de él surge un deber natural de fidelidad que los cónyuges aceptaron al manifestar su consentimiento para contraer matrimonio.

47. Consecuentemente, el incumplimiento del deber de fidelidad, entendido como un deber jurídico, tiene la consideración de conducta ilícita siendo generadora de responsabilidad en el supuesto de que provoque un daño o perjuicio moral — como la angustia mental (精神的苦痛, seishintekikutsû) 一 al cónyuge que sufre la infidelidad, siendo necesario, por supuesto, que se den los requisitos previstos por

\footnotetext{
${ }^{32}$ J. KURODA，(“不貞行為と慰謝料 — 相手方に対する請求を中心に一” (“Futeikôito isharyô —aitekatanitaisuru seikyûwo chûshin—”, “Infidelidad e indemnización —el foco sobre la responsabilidad del tercero一), 国士舘法研論集 (Kokushikan Hôken Ronshu), No. 6, 2005, p. 37.

${ }^{33}$ K. YoshIDA / T. KUwA, “民事判例研究” (“Minji hanrei kenkyû, “Estudio de jurisprudencia civil”), 北大法学論集 (Hokkaido Law Review), 71 (1), 2020, pp. 164 a 166. En relación con la citada sentencia del Tribunal Supremo japonés de 20 de julio 1936, señalan los autores, asimismo, que el fallo de la misma fue revolucionario en el sentido de que en él se reconoce la discriminación por razón de sexo en las normas relativas al divorcio — en tanto que en aquel momento solo constituía causa de divorcio la infidelidad llevada a cabo por la mujer y no la del hombre- o que el adulterio consistiese en un tipo penal únicamente previsto ante la infidelidad de la esposa (p. 164).
} 
el art. 709 CCJap, que prevé la norma general sobre responsabilidad civil, y el art. 710 CCJap, acerca de los daños no patrimoniales ${ }^{34}$ - aunque, como veremos, en el caso de la responsabilidad civil del amante del cónyuge han de concurrir asimismo otros requisitos añadidos-

\section{Tipos de responsabilidad}

\section{A) La responsabilidad civil de cónyuge infiel. Distinción entre la responsabilidad civil por divorcio y la responsabilidad civil por infidelidad}

48. En el ordenamiento jurídico japonés se distingue entre la indemnización por los daños morales ocasionados por la concurrencia de una conducta ilícita (不法行為に基づく慰謝料, fuhôikôini motozukuisharyô) conforme a lo previsto por el art. 709 CCJap - como puede ser el incumplimiento del deber de infidelidad - y, de otra parte, la posible indemnización por los daños morales derivados del divorcio en sí mismo considerado (離婚に基づく慰謝料, rikonni motozukuisharyô) en aplicación del art. 768 CCJap.

49. En lo que concierne a la indemnización por el divorcio, la pretensión de indemnización por daños morales se fundamentaría en lo previsto por el art. 768 CCJap, dedicado a la liquidación del patrimonio. Dispone tal artículo lo siguiente: «1. Cualquiera de los cónyuges que se haya divorciado por mutuo acuerdo podrá exigir del otro la partición patrimonial. 2. A falta de acuerdo, cualquiera de las partes podrá solicitar del Juzgado de Familia que adopte medidas en relación con la distribución del patrimonio a que se refiere el apartado anterior, salvo que ya hubieren transcurrido dos años desde el divorcio. 3. En el caso del apartado anterior, el Juzgado de Familia, tomando en consideración el montante del patrimonio conseguido por la colaboración de ambos cónyuges y todas las demás circunstancias concurrentes, decidirá sobre la procedencia o no del reparto, la cuantía que corresponde a cada cónyuge y el modo de realizarlo».

50. A pesar de que, a tenor de lo establecido en dicha norma, la referida indemnización por los daños morales que derivan del divorcio - y no de una hipotética conducta ilícita como la infidelidadno parece entrar dentro de lo que se consideraría la partición de los bienes entre los cónyuges, la doctrina mayoritaria japonesa y la jurisprudencia admiten la previsión de una indemnización por los daños morales ocasionados por el divorcio dentro de la liquidación del patrimonio ${ }^{35}$.

51. En cambio, el hecho de resarcir por los daños morales que derivan de la disolución del matrimonio en el seno del procedimiento de partición de bienes conyugales es una posibilidad que no se admite en nuestro ordenamiento jurídico. Esta circunstancia viene a confirmar la preocupación del ordenamiento jurídico japonés por los daños morales surgidos de las crisis matrimoniales en contraste con la postura por la que se ha optado en nuestro país, ya que la liquidación del régimen económico matrimonial se refiere en exclusiva a bienes patrimoniales.

52. Ya que lo dispuesto por el art. 768 CCJap no se circunscribe exclusivamente a la liquidación patrimonial, sino que incluye la posible compensación al cónyuge que se ve desfavorecido por el divorcio, los términos en los que se ha previsto la partición del patrimonio en el citado art. 768 CCJap nos llevaría en todo caso a pensar en la figura de la pensión compensatoria del art. $97 \mathrm{CC}$. Ahora bien,

${ }^{34}$ J. KuRODA, Op. Cit., pp. 33 y 34. En cuanto al reconocimiento del deber de fidelidad sustentado en la prohibición de la bigamia, S. MinAmiKATA, Op. Cit., pp. 77 y 78; K. ATIKAKE, “不貞行為に基づく慰謝料と離婚に基づく层謝料: 元実務家 の雑考” (“Futeikôini motozukuisharyôto rikonni motozukuisharyô: Motojitsumukano zakkô", "La indemnización basada en la infidelidad y la indemzanición basada en el divorcio: reflexiones de un antiguo ejerciente”), 山梨学院ロー・ジャーナル (Yamanashi Gakuin Law Journal), Vol. 10, 2015.

${ }^{35}$ S. Minamikata, Op. Cit., pp. 207 y 208; F. Barberán / R. Domingo, Op. Cit., pp. 387 y 388. 
lo previsto por el art. $97 \mathrm{CC}$ responde, según los casos, a la finalidad de contrarrestar el desequilibrio económico a causa del divorcio - función compensatoria - o de cubrir las necesidades de alimentos de uno de los cónyuges - función asistencial— ${ }^{36}$. Es decir, no se incluye una hipotética compensación por el sufrimiento que el divorcio pudiese ocasionar a uno de los cónyuges. Como recuerda la STS 864/2010, de 19 de enero, según la STS 43/2005, de 10 de febrero, sobre la pensión compensatoria: «[s] u naturaleza compensatoria del desequilibrio la aparta de la finalidad puramente indemnizatoria (entre otras razones, por que el artículo 97 del código Civil no contempla la culpabilidad del esposo deudor como una de las incidencias determinantes de su fijación), y del carácter estrictamente alimenticio que tendría si la prestación viniera determinada por la situación de necesidad en que se encontrara el cónyuge perceptor, lo que hace que esta Sala haya admitido la compatibilidad de la pensión alimenticia y de la compensatoria (...)».

53. No obstante, volviendo a la coexistencia de la indemnización por daños morales derivados de una conducta ilícita — como el incumplimiento del deber de fidelidad—y la indemnización por daños morales derivados del divorcio en el CCJap, resulta que, según reconocen doctrina y jurisprudencia, esta circunstancia puede resultar bastante conflictiva desde una perspectiva tanto teórica como práctica, más aún teniendo en cuenta la posibilidad de admitir la responsabilidad civil del amante del cónyuge infiel ${ }^{37}$.

54. Desde un punto de vista práctico, aunque la jurisprudencia venía admitiendo la posibilidad de que, una vez producida la partición del patrimonio, una de las partes podía solicitar el resarcimiento de los daños morales con base en lo dispuesto por el art. 709 CCJap, siempre que se considerase que los daños emocionales no fueron compensados por medio de la partición o liquidación del patrimonio, también es posible que en el procedimiento ante el Juzgado de Familia por el que se proceda a dicha partición se resuelva asimismo sobre una pretensión de indemnización fundamentada en el art. 709 CCJap — vid., art. 17 de la Ley 53/2011, de Reforma del Código de Procedimiento Civil (民事訴訟法, minjishôhô-hô) ${ }^{38}$.

\section{B) La responsabilidad civil del amante del cónyuge infiel}

55. Sin lugar a dudas, entre las diferencias que se advierten entre los ordenamientos jurídicos español y japonés acerca de la responsabilidad civil por daños morales derivados de la infidelidad conyugal, lo que más llama la atención a los ojos del jurista español es que en Japón se admita dicha responsabilidad por parte del amante del cónyuge que ha incumplido el deber de fidelidad.

56. La responsabilidad por daños morales del amante del cónyuge infiel ya fue admitido por la jurisprudencia japonesa a principios del s. XX -vid., sentencia del Tribunal Supremo japonés (大審院, daishin'in) de 1 de octubre de 1903 (大判明治36.10.1刑録9輯1425頁)-. Y, aunque dicha posibilidad se ha mantenido hasta nuestros días, con el paso del tiempo la jurisprudencia ha ido limitando su alcance, previendo los requisitos de necesaria concurrencia para la estimación de esta pretensión de indemnización.

57. En lo concerniente a la perspectiva doctrinal, YOSHIDA y KUWA enumeran las distintas posturas que han mantenido los autores japoneses sobre la eventual responsabilidad del amante del cónyuge infiel. Así pues, en primer lugar, se hallan los autores que defienden que, independientemente de la conducta del tercero, en el supuesto de que se produzca la ruptura del matrimonio, el amante del cónyuge infiel será responsable por haber llevado a cabo una conducta a todas luces ilícita. En segundo lugar, están las posturas intermedias que, en mayor o menor grado, entienden que para la apreciación de esta modalidad de responsabilidad es indispensable cierta rigidez en cuanto a los requisitos para su aprecia-

\footnotetext{
${ }^{36}$ C. Beltrá Cabello, "Pensión compensatoria", en Tratado de Derecho de Familia, M. Linacero de la Fuente (Dir.), Tirant Lo Blanch, Valencia, 2020, pp. 948 a 951.

${ }^{37}$ K. Yoshida / T. Kuwa, Op. Cit., pp. 163 y 164.

${ }^{38}$ S. Minamikata, Op. Cit., pp. 208 y 209.
} 
ción — por ejemplo, que el amante utilice la infidelidad para dañar al otro cónyuge o que se requiera que el tercero actuase empleando violencia o engaño-. Asimismo, dentro de las posturas que he denominado intermedias, se encuentra la que defiende que, una vez el matrimonio entra en crisis y, por tanto, sin necesidad de que se produzca el divorcio, los cónyuges dejan de estar obligados al cumplimiento del deber de fidelidad; de tal manera que las relaciones extraconyugales habidas a partir de ese momento no generarían responsabilidad. Por último, dentro de la doctrina japonesa se encuentran algunas voces que consideran que bajo ninguna circunstancia debe responsabilizarse al amante del cónyuge infiel por los daños morales que pudiere haber sufrido el otro cónyuge con motivo de la infidelidad ${ }^{39}$.

58. En lo que respecta a la perspectiva jurisprudencial, para la exposición de esta posibilidad admitida en el ordenamiento jurídico japonés, me basaré en la sentencia del Tribunal Supremo japonés (最高裁判所, saikô-saibansho), de 19 de febrero de 2019 (平成31.2.19民集73券2号187頁) sobre la responsabilidad por daños morales del amante del cónyuge infiel ${ }^{40}$.

59. Como hechos más relevantes acerca de la referida sentencia, nos encontramos ante un caso en el que el demandante es el marido que ha sufrido la infidelidad de su esposa y el demandado es el amante de la misma. Habiendo contraído matrimonio en marzo de 1994, fruto de dicho matrimonio nacieron su hijo en agosto de 1994 y en octubre del siguiente año su hija. Desde diciembre de 2008, la esposa entró a trabajar en la misma empresa en la que trabajaba el que luego sería su amante, siendo frecuente que la esposa no volviese a casa por motivos de trabajo. Así las cosas, el marido tuvo conocimiento de la infidelidad de su esposa en torno a mayo de 2010, si bien por aquellas fechas la relación extraconyugal ya se había extinguido. A pesar de la infidelidad de la que tuvo conocimiento el marido, el matrimonio continuó conviviendo y dicha convivencia no cesó hasta el mes de abril de 2014, coincidiendo con la entrada de su hija en la universidad, de tal manera que a fecha de 25 de febrero de 2015 los cónyuges llegaron a un acuerdo de divorcio.

60. Pues bien, en este contexto, el demandante solicita la indemnización por daños morales causados por la infidelidad conyugal al amante de su esposa, al considerar que el divorcio fue provocado por dicha relación extramarital - la infidelidad sería el acto ilícito y el daño moral la angustia sufrida por el esposo demandante - y que, por tanto, sería de aplicación lo previsto en los arts. 709 y 710 CCJap sobre la responsabilidad civil por daños.

61. Sin embargo, en la sentencia que nos ocupa se pone de manifiesto que la responsabilidad del amante del cónyuge por los daños morales ocasionados por la infidelidad se limita a aquellos supuestos en los que el tercero en discordia, además de mantener una relación con uno de los cónyuges, actuó con la intención de provocar la efectiva ruptura del matrimonio.

62. Por tanto, el Alto Tribunal japonés considera que no se dan las especiales circunstancias requeridas para el reconocimiento de la responsabilidad por daños morales del amante del cónyuge infiel con base en los siguientes motivos: en primer lugar, la relación matrimonial se encontraba en crisis antes de que tuviese lugar la infidelidad de la esposa - se indica en la sentencia que cuando ella entró a trabajar en la empresa donde conoció al que sería su amante ya no mantenía relaciones íntimas con su esposo-; segundo, cuando el marido tuvo conocimiento de la infidelidad, dicha relación extraconyugal ya había terminado y, por último, una vez descubierta la infidelidad, los cónyuges mantuvieron la convivencia durante cuatro años.

63. Con esta última sentencia del Tribunal Supremo japonés, se reitera su jurisprudencia consolidada acerca de los requisitos que han de concurrir para la apreciación de responsabilidad civil por da-

\footnotetext{
${ }^{39}$ K. Yoshida / T. Kuwa, Op. Cit., pp. 162 a 167.

${ }^{40}$ Resumen de la sentencia traducida al inglés disponible en el siguiente enlace: https://www.courts.go.jp/app/hanrei_en/ detail?id $=1633$
} 
ños morales por el amante del cónyuge infiel, conjugando, por tanto, el mantenimiento de la protección de la vida conyugal y el respeto del libre desarrollo de la personalidad — vid., sentencia del Tribunal Supremo japonés de 26 de marzo de 1997 (最三小判平成8.3.26民集50券4号993頁), que destaca al considerar que no es posible apreciar responsabilidad por parte del amante del cónyuge infiel cuando el matrimonio ya estuviese roto en el momento en el que tuvo lugar la referida infidelidad-.

\section{Conclusiones}

64. A un mismo problema, como el de la responsabilidad civil nacida del incumplimiento del deber conyugal de fidelidad, y sin que se encuentre expresamente regulado ni por el Código Civil español ni el japonés, cada uno de estos dos ordenamientos jurídicos ha optado por soluciones contrapuestas que se fundamentan, en primer lugar, en la naturaleza jurídica que se le atribuye al deber de fidelidad conyugal y, en segundo lugar, en la determinación del alcance de la responsabilidad civil en las relaciones matrimoniales.

65. En cuanto a la interpretación que realizan la doctrina y la jurisprudencia japonesas mayoritarias sobre el contenido propio del matrimonio y la protección que merece dicha institución, destaca que, a pesar de no preverse en el Código Civil japonés el deber de fidelidad entre cónyuges, dicho deber se deduce de la consideración del matrimonio como institución monógama - estando prohibida la bigamia - y su incumplimiento constituye la comisión de una conducta ilícita. De este modo, en el ordenamiento jurídico japonés se ha optado por la consagración del deber de fidelidad como auténtico deber jurídico.

66. Acerca de la responsabilidad civil nacida en el seno de una relación matrimonial, se comprueba que en Japón reviste especial importancia la protección del cónyuge por el sufrimiento que pueda padecer a causa del divorcio en sí mismo considerado o de los motivos que hayan provocado la ruptura conyugal. De hecho, el hipotético daño moral que hubiese podido sufrir uno de los cónyuges no solo puede resarcirse por la vía de la responsabilidad civil, sino que, además, puede tomarse en consideración a la hora de proceder a la partición de los bienes.

67. Si se trasladasen a España las medidas previstas en Japón sobre la responsabilidad civil por los daños morales derivados del incumplimiento del deber de fidelidad, habría de plantearse qué aceptación tendrían y cuál sería su impacto en la práctica jurídica. Tal vez, como advierten algunos autores, admitir esta modalidad de responsabilidad tendría un impacto negativo provocado por el aumento de la conflictividad en nuestro país. Ya que, aparte de las diferencias que se reconocen entre las normas que regulan el divorcio en un país y en el otro, para la valoración de esta posibilidad hay que tener presente, asimismo, aspectos de índole cultural y social — no debe perderse de vista que la tasa de divorcios contenciosos en España es superior a la de Japón- — ${ }^{41}$.

68. A mi entender, debe partirse del hecho de que la celebración de un matrimonio es un acto de libre voluntad y que supone la aceptación de los derechos y deberes a él inherentes —entre los que se incluye el deber de fidelidad-. En consecuencia, una vez contraído matrimonio, antes de incumplir cualquiera de los deberes conyugales, siempre se puede optar por la separación o el divorcio. El matri-

\footnotetext{
${ }^{41}$ De acuerdo con el Instituto Nacional de Estadística, según la versión actualizada de su nota de prensa de 28 de septiembre de 2020, el 78,9\% de los divorcios que tuvieron lugar en 2019 en España fueron de mutuo acuerdo, de manera que el $21,1 \%$ restante fueron contenciosos. En cambio, según el Portal de Estadísticas de Japón, en 2019 el $88.1 \%$ de los divorcios en dicho país fueron de mutuo acuerdo. Ahora bien, dadas las diferencias entre las distintas modalidades de divorcios en ambos países, en Japón únicamente el 1\% de los divorcios fueron de tipo de contencioso. Enlace web del INE: https://www.ine.es/dyngs/INEbase/es/operacion.htm?c=estadistica_C\&cid=1254736176798\&menu=ultiDatos\&idp=1254735573206 Enlace web del Portal de Estadísticas de Japón: https://www.e-stat.go.jp/en/stat-search/files?page=1\&query=types\%20divorce\%20\&layout=dataset\&to ukei $=00450011 \&$ tstat $=000001028897 \&$ stat_infid $=000031981603 \&$ metadata $=1 \&$ data $=1$
} 
monio no es indisoluble y la separación o divorcio no requieren la concurrencia ni de justa causa ni de la voluntad del otro cónyuge. Y, aunque es cierto que nadie tiene derecho a ser amado, tampoco nadie tiene la obligación de casarse.

69. A partir de esta consideración, creo que, en aquellos supuestos en los que la infidelidad se produce concurriendo circunstancias de gravedad o de manera reiterada, tampoco parece razonable excluir de manera tajante la responsabilidad civil por los daños morales que pudiese provocar el cónyuge infiel. Y no me estoy refiriendo a las posibles consecuencias de una conducta negligente por parte del cónyuge infiel - como la ocultación de la paternidad del amante de los hijos habidos en el matrimonio-, sino a la infidelidad propiamente dicha. Por tanto, con el establecimiento de unos criterios rigurosos para la estimación del resarcimiento de este tipo de daños, entiendo que no se correría el peligro de llegar al absurdo de indemnizar por el simple sufrimiento que de ordinario puede provocar a cualquier persona la infidelidad del cónyuge. 